\title{
NARRATIVAS DE APRENDIZAGEM DE LÍNGUA INGLESA: CRENÇAS DESVELADAS NO DISCURSO DE DOCENTES
}

\author{
Graciene Verdécio de Gusmão ${ }^{1}$
}

\begin{abstract}
Resumo: Esta pesquisa de cunho qualitativo-interpretativista buscou investigar as crenças de professores sobre o processo de aprendizagem de Língua Inglesa a partir de suas narrativas de aprendizagem. O corpus foi constituído de narrativas de aprendizagem de Língua Inglesa de professores disponíveis no banco de dados do projeto Aprendendo com Memórias de Falantes e Aprendizes de Língua Estrangeira (AMFALE), da Faculdade de Letras (FALE), da UFMG. Os resultados desta análise foram significativos, pois possibilitaram uma reflexão sobre as políticas de formação de professores de línguas vigentes no Brasil, bem como despertaram a necessidade de repensá-las, com vistas a uma possível (re)formulação, no intento de buscar subsídios inovadores para enfrentar os desafios latentes no atual ensino escolarizado brasileiro.
\end{abstract}

Palavras-chave: Crenças. Formaçáo docente. Ensino e Aprendizagem. Língua Inglesa. Narrativas.

\section{NARRATIVES OF ENGLISH LANGUAGE LEARNING: APPLIED BELIEFS IN THE SPEECH OF TEACHERS}

\begin{abstract}
This present work, a research of qualitative-interpretative had as an objective to seek and investigate the beliefs of the teachers about the process of learning the English language from their narratives of learning. The corpus has been consisting of narratives of English language learning teachers available in the database of the project Learning with Memories of Speakers and Learners of a Foreign Language (AMFALE in Portuguese) of the Language College (FALE), UFMG. The results of this analysis were significant because it was enabled to make a reflection on the training policies of language teachers in Brazil, as well as awakened the need to rethink them, with a view to a possible reformulation, in attempt to get innovative subsidies for latent challenges in the current school education.
\end{abstract}

Keywords: Beliefs. Teacher Training. Teaching and Learning. English Language. Narratives.

1 Mestra em Linguística pela Universidade do Estado de Mato Grosso (UNEMAT). Professora da Universidade do Estado de Mato Grosso (UNEMAT), câmpus de Barra do Bugres/MTBrasil. Professora no curso de Letras (Português/Espanhol), da Universidade do Estado de Mato Grosso - UNEMAT e Universidade Aberta do Brasil - UAB, na Modalidade Educação a Distância - EAD. E-mail: graciene.verdecio.gusmao@gmail.com 


\section{INTRODUÇÃO}

Proponho, neste artigo, pesquisar as crenças expressas por professores sobre o processo de aprendizagem de Língua Inglesa através de narrativas de aprendizagem. O estudo pretende também refletir acerca de possíveis caminhos para uma formação de professores de línguas, designadamente de LE/LI mais condizente com o momento sócio-histórico que a sociedade está vivenciando contemporaneamente a partir da era da globalização que irrompeu fronteiras e, juntamente com ela, encontra-se a Língua Inglesa a qual se tornou um meio linguístico essencial para os indivíduos $\mathrm{da} / \mathrm{na}$ modernidade.

Partindo deste pressuposto, a formação do docente de língua (s) materna e/ou estrangeira e idealizações de práticas de ensino são temas emergentes na atualidade. E sabido que o curso de licenciatura plena em Letras, em consonância com a legislação vigente, tem como finalidade formar docentes para atuarem na educação básica, todavia, no tempo pós-moderno em que a esfera educacional está inserida, é possível asseverar que o processo de ensino de línguas é desafiador, implicando que os professores, especificamente de LE/LI, sejam dotados de diversas competências para atender as demandas exigidas nesse contexto.

Sob esta premissa, é fundamental que os professores de línguas tenham uma sólida formação acadêmica na graduação, o que se mostra importante desafio, visto que o professor formador necessita estar em consenso, também, com as demandas exigidas fora da universidade, com o propósito de melhor preparar os futuros professores para enfrentar os desafios do dia a dia escolar.

Nesse sentido, o objetivo desse estudo consiste em analisar crenças de professores sobre o processo de aprendizagem de Língua Inglesa, a partir de suas narrativas de aprendizagem compiladas em arquivos pelo banco de dados do projeto Aprendendo com Memórias de Falantes e Aprendizes de Língua Estrangeira (AMFALE) $)^{2}$, coordenado pela professora pesquisadora Dra. Vera Lúcia Menezes de Oliveira e Paiva, da Faculdade de Letras (FALE), da Universidade Federal de Minas Gerais (UFMG), o qual tem um site na $W_{e} b^{3}$ e é financiado pelo CNPq.

Diante do exposto, pois, apresenta-se a seguir o arcabouço teórico que serviu como aporte para a análise dos dados, a saber: o construto teórico de crenças e seu desenvolvimento em Linguística Aplicada e uma breve discussão sobre os desafios na formação de professores de línguas no século XXI.

\section{O CONSTRUTO TEÓRICO DE CRENÇAS}

Diversos pesquisadores da área da Linguística Aplicada afirmam que o conceito de crenças mantém uma relação de interdisciplinaridade com a Filosofia (PEIRCE, 1877), Educação e Psicologia Educacional (DEWEY, 1933; KRUGER,

2 Vide mais detalhes sobre o projeto AMFALE nas páginas 14 e 15, deste artigo.

3 www.veramenezes.com/amfale.htm 
1993; PACHECO, 1995; RAYMOND E SANTOS, 1995; SADALLA, 1998; DEL PRETTE E DEL PRETTE, 1999; MATEUS, 1999; e ROCHA, 2002), Sociologia (BOURDIEU, 1987, 1991) e Psicologia Cognitiva (ABELSON, 1979; POSNER et. Al., 1982; NESPOR, 1987).

Os autores pioneiros na pesquisa sobre crenças referentes ao processo de ensino e aprendizagem de LE, no Brasil, que investigaram sobre esse tema foram Leffa (1991), Almeida Filho (1993) e Barcelos (1995).

Leffa (1991) realizou sua investigação em uma escola pública estadual e objetivou saber sobre as concepções dos alunos em relação à linguagem e aprendizagem de LE de um grupo de 33 alunos de $5^{\text {a }}$ série, de classe média baixa, os quais não haviam passado pelo processo de aquisição de uma LE. A coleta dos dados deu-se através de solicitações de histórias pré-orientadas aos alunos no intuito de alcançar o objetivo proposto para a pesquisa. Os resultados da investigação mostraram que os alunos têm a visão de que o processo de aquisição de LE serve para aprender novas palavras da língua-alvo, e que a Língua Inglesa é apenas mais uma disciplina no currículo escolar.

Almeida Filho (1993) utilizou o termo como "abordagem ou cultura de aprender línguas", definindo-o como:

maneiras de estudar e de se preparar para o uso da língua-alvo consideradas 'normais' pelo aluno, e que são típicas de sua região, etnia, classe social e até do grupo familiar restrito em alguns casos transmitidas como tradição, através do tempo, de forma naturalizada, subconsciente, e implícita (ALMEIDA FILHO, 1993, p. 13).

Assim sendo, a cultura, abordagem ou crenças de aprender, segundo o autor, podem influenciar todo o processo de aprendizagem da LE, uma vez que são consideradas como uma das forças operantes no modelo de operação global do ensino de línguas. Almeida Filho (1993) afirma, também, que a cultura de aprender do aluno precisa estar em consonância com a cultura de ensinar do professor, pois a ausência desta pode suscitar a resistência dos alunos no processo de aprendizagem.

Ainda outro estudo, também considerado relevante, sobre crenças foi a pesquisa desenvolvida por Barcelos (1995), a qual segue a mesma linha de pensamento de Almeida Filho (1993), utilizando o termo "cultura de aprender línguas". A autora objetivou assinalar a cultura de aprender línguas de acadêmicos formandos de Letras, de uma instituição pública de ensino superior, cuja habilitação era em Língua Portuguesa e Língua Inglesa. Os dados foram obtidos através de questionários abertos, de entrevistas semiestruturadas (gravadas em áudio), com perguntas baseadas nos questionários, de gravação de aulas em áudio e vídeo, diários da professora-pesquisadora e notas de campo. Barcelos adotou, como fundamentação de sua pesquisa, a seguinte definição do termo "cultura de aprender línguas":

Conhecimento intuitivo implícito (ou explícito) dos aprendizes constituído de crenças, mitos, pressupostos culturais e ideais sobre como aprender línguas. Esse conhecimento, compatível com sua idade e nível socioeconômico, é 
baseado na sua experiência educacional anterior, leituras prévias e contatos com pessoas influentes (BARCELOS, 1995, p.40).

As análises apresentadas por Barcelos (1995) relativas à "cultura de aprender línguas" dos alunos apontam que: a imagem do curso de Letras é negativa; a expectativa dos alunos em relação ao curso era de sair falando fluentemente a Língua Inglesa, para ensinar e, respectivamente, ter eficiência no processo de ensino; as escolas de idiomas eram os locais ideais para se aprender LE/LI, por oferecerem métodos eficientes, professores fluentes na língua alvo e capacitados para fazer com que o aluno aprenda integralmente as 4 habilidades da língua; o professor é o responsável pela aprendizagem do aluno, ou melhor, o ensino centrado no professor; a imagem da escola pública é negativa, pois acreditam que os professores são despreparados para ensinar a Língua Inglesa; a música como atividade preferida pelos alunos, pois é uma atividade lúdica, que amplia o vocabulário através da tradução; o processo de ensino/aprendizagem focado na gramática, ou seja, aprender inglês é saber sobre a gramática e estrutura da língua; ler bastante para tentar falar como o falante nativo da língua-alvo; não traduzir; e, a Língua Inglesa é mais fácil do que a Língua Portuguesa.

Podemos inferir que os resultados da pesquisa, consoante Barcelos (1995, p. 122-126), resumem-se em três crenças centrais, a saber: o processo de ensino/ aprendizagem focado na gramática, ou melhor, na estrutura gramatical da LE/LI; o processo de ensino centrado no professor; a aquisição da Língua Inglesa ocorrida "aqui" não é a mesma aprendida "lá" (exterior).

A autora ressalta que as crenças sobre a aprendizagem de LI detectadas em sua pesquisa podem ser reflexos de experiências anteriores de aprendizagem de línguas dos alunos, focando estruturas gramaticais em detrimento da comunicação, resultando em alunos que "adotam uma atitude passiva, acrítica, de não engajamento na atividade de aprender línguas" (BARCELOS, 1995, p. 124). É relevante salientar que, em outro momento, Barcelos $(2004,2006,2007)$ passa a empregar o termo crenças, como veremos na sequência.

Segundo Barcelos (2004, p. 132), há uma consonância entre as definições de crenças, pois todas são atinentes "à natureza da linguagem, aprendizagem de línguas e ao ensino/aprendizagem de línguas", além de focalizarem o aspecto cultural e social das crenças como instrumentos auxiliares dos alunos na interpretação de suas experiências de aprendizagem de línguas. Portanto, as crenças são cognitivas, porém sociais também, uma vez que sua origem é decorrente de nossas experiências vivenciadas, interações em determinados contextos, bem como da nossa aptidão de refletir e pensar sobre o que nos cerca.

Podemos constatar, também, no trabalho da pesquisadora (2004), um relato sobre as três fases da pesquisa de crenças sobre o ensino de línguas:

I. Na primeira fase da pesquisa sobre crenças, o contexto e a perspectiva do aluno não eram levados em consideração; o instrumento de coleta de dados para a investigação era restrito, pois era apenas através de questionário, resultando em uma pesquisa pouco confiável; 
II. Na segunda fase, a visão de crenças era como parte da memória e da cognição, objetivava apenas classificar as crenças e não observar o que os alunos acreditavam, sendo, portanto, crenças descontextualizadas. Podese assegurar que esta fase foi mais prescritiva;

III. $\mathrm{Na}$ terceira fase, iniciam-se usos de diferentes metodologias, as crenças são investigadas contextualmente, além de ações serem levadas em consideração na identificação das crenças.

A investigação de Barcelos (2006, p. 18-20) sintetiza como as crenças estão sendo idealizadas na contemporaneidade, conforme seguem:

1. Dinâmicas, pois mudam de um período para outro;

2. Emergentes, socialmente construídas e situadas contextualmente, visto que não são estruturas mentais prontas e fixas, uma vez que mudam e se desenvolvem à medida que interagimos e modificamos nossas experiências e somos ao mesmo tempo modificados por elas;

3. Experienciais, por se tratar de resultado das interações entre indivíduo e ambiente, entre aprendizes, entre aprendizes e professores e ser parte das construções e reconstruções das experiências dos aprendizes;

4. Mediadas, pois podem ser vistas como instrumentos, ferramentas que podem ser utilizadas ou não dependendo da situação, tarefa e interação entre os indivíduos;

5. Paradoxais e contraditórias, uma vez que podem agir como instrumentos de empoderamento ou como obstáculos para o ensino e aprendizagem de línguas;

6. Relacionadas à ação de uma maneira indireta e complexa, já que não necessariamente influenciam ações;

7. Não tão facilmente distintas do conhecimento, visto que não se separam facilmente de outros aspectos como conhecimento, motivação e estratégias de aprendizagem.

Podemos asseverar que, diante das características da natureza das crenças congregadas por Barcelos (2004, 2006), as discussões teóricas concernentes às definições de crenças como não somente individuais, mas também sociais e contextuais já começam a ganhar terreno.

Destarte, a definição do termo crenças de Barcelos (2004, 2006, 2007) corrobora o objetivo da presente pesquisa, uma vez que pretendo identificar através das narrativas de experiências de aprendizagem de LE/LI de professores, os fenômenos/crenças expressos pelos mesmos, sobre o processo de aprendizagem desta L2, sendo suas experiências de aprendizagem resultantes de vivências individuais, sociais, nas quais sofreram fortes influências de fatores como: contexto de ensino, professor, material didático, abordagem de ensino, dentre outros.

Na subseção que segue, apresento uma breve discussão sobre os desafios na formação de professores de línguas no século XXI. 


\section{OS DESAFIOS NA FORMAÇÃO DE PROFESSORES DE LÍNGUAS NO SÉCULO XXI}

No Brasil, foi a partir século XX que as discussões referentes à formação de professores emergiram, a datar da insatisfação do Ministério da Educação com o polêmico modelo seguido por inúmeras universidades em que os professores cursavam três anos de disciplinas de conteúdo específico e um ano de disciplinas pedagógicas na Faculdade/Departamento de Educação como pré-requisito para a obtenção da licenciatura $^{4}$ (GATTI, 2010; PAIVA, 2013).

No início de 2002, o Conselho Nacional de Educação (CNE/CP) instituiu duas resoluções, sendo a primeira referente às "Diretrizes Curriculares Nacionais para a Formação de Professores da Educação Básica, em nível superior, curso de licenciatura, de graduação plena"; e a segunda, alusiva às atividades práticas dos cursos de licenciatura, os quais passariam a cumprir carga horária de 300 horas designadas para o estágio docente e 500 horas para as demais práticas acadêmicas (PAIVA, 2013, p. 9).

A primeira resolução teve como intento central retificar uma lacuna que, por muitos anos, perdurou, em que a responsabilidade pela formação de professores de Línguas recaía sobre a Faculdade/Departamento de Educação. A pesquisa enfocada no processo de ensino e aprendizagem, bem como a práxis do professor em préserviço ganham o devido espaço na grade curricular dos cursos de licenciatura nas universidades brasileiras (PAIVA, 2013).

Cumpre ressaltar que Paiva (2013) expõe, sob o aporte da primeira resolução, que a articulação da pesquisa sobre o processo de ensino e aprendizagem e a capacitação prática devem desenvolver-se não somente no nível micro da universidade (dentro da universidade), mas também no nível macro da mesma (fora da universidade).

A autora conclui que as intervenções legais impactaram positivamente a formação dos professores, dando oportunidade aos profissionais da área de pesquisar e, consequentemente, de oferecerem sua parcela de contribuição com vistas a uma competência profissional mais eficaz. Presentemente a área de formação de professores, especificamente de Letras, consolidou-se abarcando, em suas pesquisas, filiações institucionais e teóricas diferentes.

Gatti (2010, p. 1357) também faz uma retomada histórica sobre a formação de professores no contexto brasileiro e assevera que, por mais que tenha ocorrido a instituição das novas diretrizes que orientam acerca da relação "formação disciplinar/formação para docência", no contexto contemporâneo, ainda prevalece o polêmico "modelo consagrado no início do século XX [nas] licenciaturas". Ou seja, nos moldes de "representação tradicional e nos interesses instituídos",

4 O referido modelo foi versado popularmente como $3+1$, o qual era integrado nas grades curriculares dos cursos de Letras das universidades brasileiras da época (GATTI, 2010; PAIVA, 2013). 
impossibilitando, dessa forma, de ao menos se tentar fazer uma reformulação da formação de maneira mais integrada e sob novos embasamentos (GATTI, 2010, p. 1359).

Partindo do macro em relação à formação de professores, a qual acabo de apresentar, para o micro, tomo como ponto de partida, para esta discussão sobre os desafios na formação de professores de línguas no século XXI, a pesquisa de Siqueira (2012), que trata dos desafios aguardados pelos profissionais de Letras no tempo presente, em meio à diversidade humana, em que os profissionais da área da linguagem ocupam um lugar de suma importância, pois, com a nova ordem mundial, surgiram novos paradigmas em todos os setores da vida do indivíduo.

Assim, conforme assevera o autor, é imprescindível a preparação desse indivíduo para que exerça seus deveres e saiba cobrar os seus direitos no mundo globalizado que estamos vivenciando e, por conseguinte, consiga garantir sua cidadania intercultural e, um dos meios de oferecer tal preparação, é através da promoção de uma pedagogia voltada para a educação linguística desse indivíduo, interligando a diversidade, ensino e linguagem.

Em Siqueira (2008; 2010; 2012), podemos observar uma lista com algumas características que o autor julga necessárias aos profissionais de Letras, sobretudo aos professores de línguas, pensando a diversidade, ensino e linguagem na contemporaneidade; observemos uma súmula das mesmas no quadro 1:

Quadro 1: Características necessárias aos professores de línguas, pensando a diversidade, ensino e linguagem na contemporaneidade compiladas por Siqueira (2008; 2010; 2012) sintetizadas pela autora desta pesquisa.

\section{CARACTERÍSTICAS NECESSÁRIAS AOS PROFESSORES DE LÍNGUAS, PENSANDO A DIVERSIDADE, ENSINO E LINGUAGEM NA CONTEMPORANEIDADE}

- ... reconheça a dimensão política que essencialmente envolve o ensino de línguas/literaturas, isto é, todo trabalho com a linguagem;

- ... busque a formação de educador linguístico, não de técnico de ensino;

- ... ajude o seu aluno a ver o acesso a línguas (materna e estrangeira) como um de seus direitos mais importantes na busca pela condição de cidadão planetário;

- ... seja autônomo o bastante para desafiar certos cânones ideológicos e metodológicos;

- ... questione teorias de ensino e aprendizagem de caráter universalizante;

- ... entenda-se como um professor-pesquisador (não cobaia de pesquisas), contribuindo para o desenvolvimento de uma epistemologia local;

- ... entenda-se como um pedagogo intercultural crítico, como um mediador cultural;

- ... incumba-se da "desestrangeirização" da língua cultura que ensina, seja materna ou estrangeira (ALMEIDA FILHO, 1998);

- ... capacite-se para lidar com qualquer aprendiz, em especial, os mais jovens e aqueles oriundos de camadas populares, de grupos marginalizados, de minorias;

- ... enfatize e trabalhe o caráter emancipatório do ato de ensinar e a importância de nos tornarmos multilíngues na nossa LM e na LE alvo; 
- ... dê acesso às literaturas não canônicas, aos falares diversos das línguas que ensina, respeitando e valorizando as diferenças, as "localidades";

- ... procure o quanto antes descobrir as reais necessidades de seus aprendizes e planeje suas aulas não para cumprir a sua agenda, mas a do seu aluno;

- ... analise criticamente currículos, programas e materiais didáticos, promova discussões, simulações, e até 'alucinações', a partir de temas e situações reais, descartando a ideia de transformar a sala de aula numa 'ilha da fantasia';

- ... assuma-se como falante/usuário não-nativo de uma língua estrangeira (LE), livre de tutelas culturais e ideológicas e da obrigação de servir de protótipo de falante nativo.

Como averiguamos nas características necessárias aos professores de línguas, pensando a diversidade, ensino e linguagem na contemporaneidade compiladas por Siqueira $(2008$; 2010; 2012), as quais foram sintetizadas pela autora desta pesquisa, os desafios do professor formador têm uma dimensão expressiva, já que a empreitada dos profissionais de línguas em pré-serviço fora dos bancos da universidade, evidentemente, não será nada fácil, visto que são múltiplos os atributos que o pesquisador presume serem vitais aos profissionais que lidarão com a educação linguística; dentre eles, fatores linguísticos, culturais, políticos, sociais e ideológicos.

Portanto, corroboro com Siqueira (2012), que assevera que os profissionais de Letras, que certamente vão se deparar com esses empecilhos em seu cotidiano de trabalho, precisam ser "transpostos desde a sua formação e ao longo de sua carreira, de maneira contínua" (SIQUEIRA, 2012, p. 56). Concordo, outrossim, com a assertiva de Siqueira (2012), quando orienta que, para essa formação do professor de Letras realmente acontecer de forma efetiva, é necessário que os professores formadores tenham plena consciência desses entraves que os alunos-professores enfrentarão concernentes à educação linguística na realidade educacional. E, assim, proporcionar aos professores em pré-serviço o ensino da prática pedagógica como uma ação política, para que os mesmos instruam seus educandos, principalmente aqueles que vivem à margem social.

Destarte, creio que seja necessário repensar as políticas de formação de professores de línguas no Brasil, com vistas a uma possível (re)formulação dessas políticas de formação, para enfrentar tais desafios, como os apontados por Siqueira (2012), por exemplo, e tantos outros, que estão presentes no ensino escolarizado brasileiro hoje.

Dentro desta perspectiva, temos os estudos de Freitas (2004), Vieira-Abrahão (2012), Cristovão (2013), Gimenez (2013a e 2013b) e Silva (2013), os quais elencam críticas referentes à formação de professores de línguas no contexto nacional, bem como apresentam sugestões que, segundo seu entendimento, se fossem implementadas nos cursos de formação, suscitariam mudanças significativas nas políticas de formação e, concomitantemente, melhorariam o processo de preparação dos futuros profissionais que atuarão no âmbito educacional complexo da atualidade. 
Freitas (2004), em sua investigação acerca do perfil desejado pela educação contemporaneamente, do professor de línguas e, respectivamente, de seus alunos, assevera que, para que a formação dos futuros profissionais de ensino de línguas seja condizente com os tempos atuais em que se encontra a educação, é vital que não esteja fundamentada nos moldes tradicionais, através do ensino conteudista, tecnicista, acordada com uma infinidade de estratégias.

A estudiosa afiança que, a tendência para a formação dos professores na contemporaneidade é voltada para um profissional reflexivo crítico comprometido com sua formação, que se envolva politicamente nas deliberações educacionais, que faça uso de diferentes áreas do conhecimento em seu exercício pedagógico e, por fim, que a partir da sua atuação em sala de aula pratique e agencie a cidadania (FREITAS, 2004).

As proposições de Vieira-Abrahão (2012) concernentes à formação do profissional de línguas sob uma perspectiva sociocultural indicam que, nos cursos de formação de professores de línguas, há, ainda, a preponderância do treinamento de técnicas específicas, precedidas de transmissão de conhecimentos resultantes de investigações consolidadas na área de Linguística Aplicada e Aquisição de Línguas, o que institui uma lacuna em grande parte dos cursos de formação destes professores.

A autora pondera que, nos dias atuais, seria de grande valia se os cursos de formação de professores de línguas tivessem como alicerce do ensino a perspectiva sociocultural, em que a aprendizagem do professor em pré-serviço é vista como um processo dialógico de coconstrução de conhecimentos, centrados e insurgidos da participação em práticas e âmbitos socioculturais. Assim sendo, na perspectiva sociocultural, "a aprendizagem do professor e as atividades de ensino são compreendidas como originárias das participações dos docentes nas práticas sociais" (VIEIRA-ABRAHÃO, 2012, p. 460).

Cristovão (2013) oferece sugestões de possíveis caminhos a trilhar para a construção de uma política de formação de professores de línguas no Brasil, mais condizente com os paradigmas emergentes na atualidade. A autora critica a limitação à formação técnica na qual o professor em pré-serviço recebe e executa os saberes adquiridos na universidade, modelo este, ainda, seguido em muitos cursos de graduação em línguas nacional. Defende que os currículos de formação de professores de línguas deveriam ser mais abertos e menos rígidos.

A pesquisadora, ao fazer suas críticas, propõe que a formação de professores de línguas deveria ser orientada para uma formação de alunos-professores intelectuais críticos, engajados e comprometidos com um ponto de vista da escola como um espaço público democrático. Uma formação que não se restrinja aos muros da universidade e ao estágio de observação e/ou supervisionado, mas que seja um processo que possa se desenvolver em diferentes contextos, como na escola como um todo e em outros espaços.

Cristovão (2013) porém salienta que há algumas implicações para que todas as suas sugestões sejam realmente colocadas em prática, no curso de formação de 
professores de línguas, entre elas, está a necessidade de implementação de projetos, inclusão de conteúdos sobre políticas educacionais, produções críticas de materiais didáticos visando auxiliar as práticas docentes e maior incentivo aos trabalhos de pesquisa, durante o percurso de preparação dos licenciandos.

Gimenez (2013a), em sua pesquisa a respeito dos avanços e desafios na formação de professores de línguas no Brasil, afirma que a quantidade de horas no currículo de formação de professores de línguas em nosso país não poderia ser insuficiente; as organizações curriculares dos cursos de formação de profissionais de línguas não deveriam ser divorciadas de práticas escolares como ainda são presentemente, reforçando, assim, a dicotomia teoria/prática; não deveria ter o predomínio da racionalidade técnica na construção curricular das licenciaturas em Letras; não deveria prevalecer a visão de bacharelado, ou seja, formação voltada apenas para pesquisa, ao invés de formação para docência e pesquisa.

Em seguida, Gimenez (2013a, 2013b) sugere que, para a superação desses entraves na formação de professores de línguas, seria fundamental que se desenvolvesse uma formação inicial sob a visão de comunidade de práticas, a partir da qual se promovessem situações geradoras de novas identidades e, consequentemente, de aprendizagem. A comunidade de prática na formação préserviço pode ser entendida como o engajamento do aluno-professor em práticas profissionais no contexto da comunidade escolar. Assim sendo, a formação inicial de professores sob esse viés sai dos moldes tradicionais arraigados, ainda, em muitas instituições de ensino superior brasileiras, concedendo abertura para implementação de um ensino inovador.

Já Silva (2013), em seu trabalho sobre a importância do estudo das crenças sobre o ensino e a aprendizagem de línguas nos programas de formação de professores, assevera que a formação de professores de línguas hoje não pode ser desenvolvida para fins de transmissão de conhecimentos, para que o licenciando aplique futuramente esses conhecimentos adquiridos em sala de aula.

Sob o ponto de vista do autor, a formação de professores de línguas será mais eficiente se houver a consideração da importância das crenças e da conscientização das mesmas pelos alunos-professores, uma formação conduzida sob um processo contínuo de ensino reflexivo e crítico no desígnio de desenvolver a criticidade e a emancipação do profissional do ensino. Portanto, o paradigma de ensino críticoreflexivo direciona o futuro educador a ser capaz de pesquisar sua "[...] abordagem de ensinar, refletir sobre ela e estar consciente das crenças sobre o ensinoaprendizagem que permeiam sua prática pedagógica e das suas possíveis origens" (SILVA, 2013, p. 31).

É interessante salientar que tenho plena convicção de que não se deve abrir mão do uso de nortes teórico-metodológicos nos cursos de formação de professores de línguas, pois eles fazem parte desse processo, no entanto, entendo que não se pode lançar mão deles exclusivamente, deixando de lado outras opções como as articuladas nesta seção que são, também, de extrema significância. 
Assim, após apresentar o aporte teórico deste artigo científico, na próxima seção, descrevo os procedimentos metodológicos de que fiz uso para a condução desta investigação.

\section{METODOLOGIA DE PESQUISA}

No presente estudo, adotei a pesquisa de natureza qualitativa do tipo interpretativista (BOGDAN e BIKLEN, 1994; ANDRÉ, 1995), pois o objetivo foi o de produzir um relato descritivo, interpretativo, exploratório das narrativas de aprendizagem de Língua Inglesa de professores de LI, no intuito de identificar as crenças elucidadas pelos mesmos, nos seus rememorandos das empreitadas vivenciadas na construção de seus conhecimentos de LE/LI.

Segundo Barcelos (2006), as pesquisas de Telles (2000, 2002, 2004) chegaram à conclusão de que a pesquisa narrativa serve como referência para quem pretende lançar mão de investigações sob esse viés, pois, por meio desta abordagem, o pesquisador tem a possibilidade de ter acesso aos pensamentos e experiências de professores.

Por meio da pesquisa narrativa, tem-se a oportunidade de identificar fenômenos linguísticos, através de rememorações, histórias pessoais, experiências, temporalidade, sociabilidade e lugar nas reconstruções e construções de sentidos e significados expressos nas narrativas. Com a pesquisa narrativa, na condição de pesquisadores da linguagem, tem-se acesso para além de simples histórias de vidas; tem-se a oportunidade de observar e analisar fenômenos que, lançando mão de outros métodos, não seriam tão eficazes.

As narrativas de aprendizagem podem nos revelar importantes fenômenos ocorridos no processo de aquisição de segunda língua. Cumpre destacar que, para este contexto de pesquisa, não utilizei a pesquisa narrativa como método de pesquisa, mas como fenômeno estudado. Ou seja, procedi à coletânea de narrativas de aprendizagem de professores de LI no banco de dados do projeto AMFALE e, posteriormente, analisei-as, objetivando identificar os fenômenos/crenças expressos.

Os dados desta pesquisa foram coletados no banco de dados do projeto Aprendendo com Memórias de Falantes e Aprendizes de Lingua Estrangeira (AMFALE), coordenado pela professora pesquisadora Dra. Vera Lúcia Menezes de Oliveira e Paiva, da Faculdade de Letras (FALE), da Universidade Federal de Minas Gerais (UFMG), o qual tem um site na $W e b^{5}$ e é financiado pelo CNPq.

Os pesquisadores integrantes do projeto AMFALE têm como principal objetivo investigar, através de narrativas de aprendizagem de línguas estrangeiras, como se desenvolve o processo de aprendizagem da segunda língua. As narrativas de aprendizagem de segunda língua coletadas neste banco de dados são de professores em pré-serviço, bem como em serviço e de pesquisadores em geral

www.veramenezes.com/amfale.htm 
que queiram narrar suas memórias de aprendizagem de L2. Cumpre frisar que as narrativas de aprendizagem coletadas neste banco de dados não são feitas apenas por pesquisadores nacionais, existem colaboradores de universidades internacionais, também, como do Japão e Finlândia.

Dessa forma, a partir desse intercâmbio de pesquisadores de diversas universidades nacionais e algumas internacionais, as narrativas de aprendizagem de diferentes idiomas como segunda língua, como: Língua Alemã; Língua Espanhola; Língua Inglesa; Língua Italiana; Língua Francesa e Língua Portuguesa, ficam à disposição. É possível encontrar, também, narrativas de aprendizagem de língua estrangeira escritas pelos aprendizes em Língua Portuguesa e Língua Inglesa, sob a forma de texto, áudio e multimídia.

As análises das narrativas de aprendizagem de LE feitas pelos pesquisadores do projeto AMFALE são realizadas sob múltiplos vieses teóricos, a saber, crenças sobre o processo de ensino e/ou aprendizagem de línguas; a teoria do caos/ complexidade; identidades de aprendizagem; aquisição de línguas estrangeiras; formação de professores; dentre outros.

O sítio do projeto, juntamente com o banco de dados, fica disponível on-line $24 \mathrm{~h}$ no intuito de contribuir com outros pesquisadores de diferentes instituições de ensino, para o desenvolvimento de pesquisas, a partir de narrativas de aprendizagem, como é o caso desta pesquisa, desenvolvida através do aludido banco de dados.

Para esta pesquisa, foram selecionadas 50 narrativas de aprendizagem de LI de professores de L2, sendo que no banco de dados do projeto AMFALE estão disponíveis, até o presente momento, cerca de 250 narrativas. Quanto aos critérios de seleção adotados, iniciou-se com a seleção de narrativas alinhadas ao corpus desta investigação, infelizmente, o site não disponibiliza, em grande parte das narrativas, informações dos professores participantes do projeto, se são atuantes e/ou não atuantes no contexto de ensino, faixa etária, sexo, tempo de engajamento no processo de aprendizagem de LI e o local onde ocorreu esse processo, impossibilitando, pois, apresentar tais dados nesta pesquisa. Para o recorte dos dados, primeiramente, foram organizados e enumerados cronologicamente; posteriormente fez-se a leitura geral das narrativas e, em seguida, realizadas algumas anotações referentes às primeiras impressões das narrativas dos sujeitos participantes desta pesquisa. Em seguida, ocorreu uma segunda leitura indutiva intensiva das narrativas, buscando fragmentos, palavras-chave em relação às crenças. Ao encontrar os fragmentos e palavras-chave, foram sendo marcados com canetas esferográficas coloridas; depois, uma terceira leitura indutiva das narrativas com os fragmentos e palavras-chave já marcados em cores vermelho, azul, verde, rosa e laranja, no intuito de identificar categorias de crenças dos professores sobre o processo de aprendizagem de L2. Encontradas as categorias de crenças sobre a aprendizagem de Língua Inglesa, partiu-se para uma quarta leitura indutiva intensiva na intenção de relacionar às categorias de crenças, as suas subcategorias e, por fim, procedeu-se ao recorte dos dados, congregando as categorias e subcategorias de crenças. 


\section{ANÁLISE DOS DADOS}

Esta seção é dedicada à apresentação e análise dos dados coletados, os quais foram ancorados nos procedimentos teórico-metodológicos apresentados por Bogdan e Biklen (1994), André (1995), que tratam da pesquisa de natureza qualitativo-interpretativista e Paiva (2007), sob o arcabouço da pesquisa narrativa, bem como nos pressupostos teórico-metodológicos apresentados anteriormente, visando produzir um relato descritivo, interpretativo, exploratório das narrativas de aprendizagem de Língua Inglesa de professores de LI, no intuito de identificar as crenças elucidadas pelos mesmos, nos seus rememorandos das empreitadas vivenciadas na construção de seus conhecimentos de LE/LI.

\section{O processo de aprendizagem de LE/LI na instituição de ensino pública}

\section{" Crença: Náo se aprende LE/LI na instituição de ensino pública}

A partir das narrativas que seguem, é possível perceber que os professores participantes deste trabalho acreditam que não se aprende LE/LI na instituição de ensino pública. Os excertos, a seguir, realçam esta proposição:

Meu primeiro contato com a língua inglesa, foi aos 11 anos, na $5^{\mathrm{a}}$ série do Ensino Fundamental. Até a conclusão do Ensino Médio, havia na grade curricular a língua inglesa, porém, tantos anos de contato na escola secular, não foram proveitosos para a minha aprendizagem, ou seja, não aprendi a língua. (Narrativa 1).

Quando comecei a estudar inglês na $5^{\mathrm{a}}$ série eu não aprendi nada porque o professor nada sabia. E assim foi durante todo o Ensino Fundamental e Médio, entrei sem saber e sai sabendo menos. A língua inglesa nunca foi ensinada com ênfase em atividades que envolvessem os alunos, não me lembro de nenhuma aula divertida que me chamasse atenção. Era aquela aula maçante, horrível, na aula de inglês a hora não passava. (Narrativa 2).

Todos estes 7 anos e 6 meses de Língua Estrangeira foram em escolas regulares, ou seja em escolas públicas e na faculdade de Letras. Ao meu ver o ensino de línguas em escolas públicas foi sem nenhuma sequência ou algum método, até porque o número de alunos em sala é muito expansivo, sem contar o desinteresse da maioria dos alunos. [...] A escola sabe disto. (Narrativa 3).

De acordo com as narrativas 1, 2 e 3, a crença manifestada pelos professores, também se refere ao ensino de LI na escola pública, âmbito no qual não aprenderam esta segunda língua. Sob meu ponto de vista, é possível que as crenças detectadas nos excertos supracitados tenham se originado em consequência de numerosos fatores, como o perfil do professor de LE, designadamente, de LI, o qual, por vezes, leciona-a sem dominar as habilidades que competem para o exercício pleno do ensino desta língua e, em decorrência desse fato, o professor não consegue fazer uso de uma metodologia que o processo requer, tornando-se, assim, uma aula "maçante, horrível" (recorte da narrativa 2), na qual "a hora não passava" (recorte 
da narrativa 2), ou seja, uma aula desmotivadora consoante o participante desta pesquisa expressa na narrativa 2. Outro fator que identifiquei e que possivelmente contribuiu para que as crenças manifestadas na narrativa 3 emergissem foi a falta de infraestrutura na instituição de ensino pública, pois o número de alunos neste âmbito é acentuado, além da falta de interesse de muitos alunos que a frequentam.

Esta crença já foi elicitada em trabalhos anteriores de pesquisadores da área da Linguística Aplicada, como em Félix (1998); Barcelos (1995); Silva (2005); Coelho (2006); Rodrigues (2006); Santos (2010), sendo que, entre os resultados, mostraram que não se aprende Inglês na escola pública. As conclusões aqui apontadas dissentem com os resultados da investigação de Lima (2005), visto que uma das crenças percebidas em sua pesquisa foi a de que é possível aprender Inglês na escola pública.

\section{A aprendizagem de LE/LI no país de origem dessa segunda língua}

\section{" Crença: Aprende-se LI no país onde se fala essa LE}

A crença que discuto nesta seção é concernente à aprendizagem da LI no país onde se fala essa LE, as narrativas apresentadas, a seguir, asseveram esta proposição:

Eu estudei até os 16, quando eu tinha 16 nos eu fiz um ano de intercâmbio na Filadélfia onde realmente o meu Inglês desmanchou, foi uma época que, realmente fez diferença. Aí eu voltei pro Brasil, parei de estudar um pouco, voltei a estudar no Cultura também, tirei o certificado de "Cambridge", o "CAE" e o "Proficiency". Dois anos depois da faculdade eu fui para Nova York e estudei no York University um ano e meio de especialização de Língua Inglesa "English Turing" onde se aperfeiçoa métodos de ensino, onde se aperfeiçoa o sotaque você estuda muita gramática e estuda Literatura, muito completo o curso, muito bacana, aí meu aprendizado de Inglês ficou acadêmico aí de volta ao Brasil eu continuei dando aula de Inglês [...]. ( Narrativa 4).

Já tinha 3 anos que eu dava aula aí eu viajei para os EUA fiz um Intercâmbio da YMCA aquele de quatro meses que todo mundo faz porque é mais barato e tudo aí o pessoal falava: Ah! Mas você aprendeu aqui? - O "grosso", o princípio foi aqui. E como que foi isso. Eu ia para a aula e eu sempre gostei, fazia as atividades que tinha que fazer e eu acho que tenho uma facilidade assim para aprender, então, acho que funcionou bem, acho que fiz a minha parte bem feita, por isso que deu certo. Depois dos EUA, que foi uma parte bem prática, porque esse intercâmbio não é para estudar nem nada, aí: - Você vai viver com suas amigas, vai ser monitora de um monte de crianças... E aí é a parte prática do negócio (Narrativa 5).

Acredito (essa é a minha crença), que só há uma maneira de mudar esse meu problema, morar em país de língua inglesa por um período de dois a três anos, onde eu terei a oportunidade de ouvir o inglês, 24 horas por dia, 7 dias por semana, e sentiria obrigado a apurar o ouvido para o idioma (Narrativa 6). 
Nas narrativas 4, 5 e 6, é possível observar que os participantes desta pesquisa acreditam que se aprende LI no país onde se fala essa LE. No excerto 4, a professora afirma que sua aprendizagem de LI "desmanchou" (recorte da narrativa 4), ou melhor, desenvolveu-se efetivamente ao fazer um intercâmbio para a Filadélfia, sendo que a mesma acredita que depois desse período seu aprendizado de Inglês tornou-se acadêmico. Partindo da narrativa 4, pode-se inferir que está implícito na memória de aprendizagem de LI da participante que no Brasil ela não conseguiu obter fluência na língua alvo, precisou morar alguns anos no país de origem da língua para aperfeiçoar sua aprendizagem. Igualmente se pode notar no excerto 5, em que a professora expressa sua crença de que se aprende "o grosso" (recorte da narrativa 5) no Brasil e a parte prática da aprendizagem de LI se aprende nos EUA, onde se pratica a oralidade no contexto real de uso da língua. E na narrativa 6 não é diferente, pois o professor revela que acredita que somente aprenderá e/ou compreenderá integralmente a LI, especificamente a escuta da língua em questão, se "morar em país de língua inglesa" (recorte da narrativa 6) por um determinado tempo, para dialogar com falantes nativos da língua e, dessa forma, ouvi-los pessoalmente. Cumpre destacar que esta crença já foi elencada e discutida nas investigações de Barcelos (1995) e Silva (2005), os quais constataram que a aquisição da Língua Inglesa ocorrida "aqui" não é a mesma aprendida "lá" (exterior).

\section{O papel do professor de LE/LI no processo de aprendizagem do aluno}

\section{" Crença: A responsabilidade sobre a aprendizagem de LI do aluno é do professor}

A crença de que a responsabilidade sobre a aprendizagem de LI do aluno é do professor foi detectada, também, nesta dissertação, reafirmando a premissa de que o processo de aprendizagem de LE/LI é centrado excepcionalmente no professor, como se o mesmo fosse a fonte de conhecimentos. As seguintes narrativas sublimam tais crenças:

Sempre tive muita facilidade com línguas, mas acredito que o papel das minhas professoras nesse estágio tão jovem do meu aprendizado foi o que mais me incentivou. [...] Minhas professoras sempre conduziam as aulas de uma maneira lúdica o que com certeza facilitou minha aquisição da segunda língua (Narrativa 7).

Meu entusiasmo pela língua inglesa se deu ao chegar na $5^{a}$ série do Ensino Fundamental, que por ser diferente, me interessou bastante. A professora também marcou demais por ser ela a principal incentivadora para o estudo desta língua (Eu adoro inglês) (Narrativa 8).

Consoante à narrativa 7, a professora acredita que o papel de suas professoras de LI influenciou positivamente em sua aquisição de segunda língua, pois as mesmas a incentivaram a aprender esta língua por intermédio de aulas lúdicas, o que para ela significa mais facilidade em sua aprendizagem. No excerto 8, a professora 
relata que, por mais que tenha achado a LI interessante no início do seu estágio de aprendizagem, sua professora da disciplina foi a principal protagonista desse processo, uma vez que a incentivou a estudar esta língua e despertou nela o gosto pela mesma.

Era uma aluna muito indisciplinada nas aulas de inglês, talvez por causa da minha falta de interesse. Uma vez eu não parava de conversar na sala de aula e eu era daquele tipo que fazia todo mundo rir, até que o professor me chamou a atenção, fazendo uma pergunta em inglês da qual eu não consegui responder. Foi uma espécie de desmoralização diante da turma, a partir daí passei a odiar inglês, acho que só passava de ano porque uma amiga minha me ajudava a estudar. Foi assim até o $2^{\circ}$ grau [...] (Narrativa 9).

Estudei em Escola Estadual no $1^{\circ}$ e no $2^{\circ}$ grau na cidade de Pequi. Não gostava do inglês, pois a professora não motivava, não fazia nada para chamar a nossa atenção. Fui para a faculdade FAPAM em Pará de MInas fazer o curso de Letras. No $1^{\circ}$ período já tinha o inglês, passei beirando. No $2^{\circ}$ período fiquei em dependência. Não gostava do modo da professora ensinar (Narrativa 10).

A minha motivação em relação ao inglês do colégio diminuía a cada dia porque a pronúncia dos meus professores de lá era bem inferior à minha. Eu via a aula de inglês como a aula de descanso (Narrativa 11).

As narrativas 9, 10 e 11 são distintas dos excertos 7 e 8 , os quais acabo de analisar acima, pois, na narrativa 9, por exemplo, a professora revela sua memória negativa concernente ao papel de seu professor de LE/LI durante suas aulas da disciplina, visto que ela acredita que este lhe despertou ódio sobre a língua por ter lhe chamado a atenção durante sua aula. Apreende-se que mesmo a professora reconhecendo que foi uma aluna indisciplinada, ela atribui ao papel do professor a responsabilidade de ter gerado a crença do desgosto e desmotivação pela aprendizagem de LI. Nos excertos 10 e 11, as situações não são diferentes, as professoras explanam crenças de que não gostavam de aprender Inglês pelo fato de os seus professores não as motivarem ao aprendizado desta segunda língua através de atividades motivadoras, além do fato de designarem que seus professores não tinham uma boa formação profissional, o que resultou em aulas falhas com problemas metodológicos e de pronúncia da língua.

Os resultados evidenciados a partir das narrativas analisadas nesta seção já foram atestados em outras pesquisas, como a de Barcelos (1995); Silva (2005) e Rodrigues (2006), os quais identificaram a crença de que o professor é o responsável pela aprendizagem do aluno, ou melhor, o ensino é centrado no professor. Os dados analisados nesta seção se opõem às crenças reportadas nas pesquisas de Zolnier (2007) e Simões (2011), nas quais seus informantes asseveram que o aluno é o maior responsável pela sua aprendizagem. 


\section{O OUTRO VIÉS DAS CRENÇAS DOS PROFESSORES ATINENTES AO PROCESSO DE APRENDIZAGEM DE LE/LI}

A finalidade desta seção é retomar e discutir sobre as crenças detectadas no presente estudo sob o viés dos pressupostos da formação docente de línguas. Antes de começar esta discussão, entendo ser importante retomar e reafirmar a definição do termo formação. Corroboro com Porto (2004) ao afirmar que o processo de formação está ligado à experiência de vida pessoal e profissional do indivíduo, dotada de incompletude, pois está sempre em percurso durante o curso de vida do indivíduo. Assim, sob meu ponto de vista, as crenças expressas pelos professores, através de suas narrativas com suas memórias de aprendizagem de LI estão relacionadas aos seus processos de formação, podendo essas crenças terem sido originadas de experiências anteriores do aprendizado da língua alvo.

Partindo das categorias de crenças analisadas nas subseções anteriores, é possível inferir que grande parte dessas crenças apresenta fatores que envolvem a formação dos docentes dos participantes desta investigação, os quais deixaram, como legado de suas práticas pedagógicas de ensino de línguas para as memórias de aprendizagem de seus alunos, muitas crenças; parte mínima contemplada neste estudo. É possível atestar esta premissa a partir das crenças pronunciadas pelos professores, já analisadas nas subseções acima.

Também pode-se inferir, a partir das crenças enunciadas pelos professores, que o processo de ensino e aprendizagem ocorridos na escola e/ou no curso de Letras não foi suficiente para se aprender integralmente a LI. Questões relacionadas ao processo de ensino e aprendizagem de LE/LI como má qualificação profissional vêm sendo discutidas nas universidades brasileiras ao longo dos anos, entretanto, não houve avanços significativos no que concerne à melhoria da oferta desse processo, dessa qualificação profissional e demais fatores. As consequências dessas controversas para os profissionais que seguem carreira nesta área do conhecimento certamente são negativas.

Cumpre lembrar que estudiosos como: Barcelos (1995); Félix (1998); Lima (2005); Silva (2005); Coelho (2006); Rodrigues (2006); Bomfim (2008); Santos (2010) e Simões (2011) já haviam detectado as crenças identificadas nesta pesquisa, o que comprova que as problemáticas reminiscentes ao ensino e aprendizado de LE/LI e formação profissional enfrentadas pelas instituições de ensino regulares e superiores continuam latejantes.

Diante das crenças constatadas, conclui-se que o ensino de LI nas escolas permanece fragmentado, ou melhor, sem o foco nas quatro habilidades da língua. A metodologia utilizada pelos professores nesse contexto continua defasada, dificultando que aconteça, de fato, a aprendizagem dessa LE/LI. Não diferente, o processo de aprendizagem de LI na universidade está ligado à metodologia, pois professores, nesse âmbito de ensino, fazem uso de uma metodologia não condizente com o nível aprendido pelos aprendizes no ensino regular. Assim, agravam ainda mais o não desenvolvimento pleno desse processo. 
Sob meu ponto de vista, as crenças desveladas reforçam a ideia de que não se aprende LE/LI na escola pública, pelo fato de o professor não ter competência linguístico-comunicativa, um bom desempenho didático e pedagógico, o que implica a falta de conhecimento de métodos e abordagens de ensino de línguas atualizados, além da falta de infraestrutura condizente com o número excessivo de alunos em sala de aula. Creio que seja necessário repensar as políticas de línguas no contexto nacional, para que as crenças, como as identificadas neste trabalho, não perdurem ao longo dos anos, impedindo os avanços necessários para que se transforme o contexto das aulas de LE/LI.

Os resultados evidenciam que prevalece a crença de que o ensino de línguas, no Brasil, é ineficiente, enquanto que no país onde se fala essa LE, é possível se aprender fluentemente. Entendo que esta crença se sustenta no fato de que o ensino de LE/LI oferecido no Brasil tem como base preceitos da abordagem tradicional através da gramática pela gramática, não dando prioridade, por exemplo, à habilidade comunicativa da língua. Sob minha concepção, esta visão do lugar que se aprende línguas no país falante desta LE precisa ser desmistificada, uma vez que é presumível aprender todas as habilidades de uma LE sem necessariamente ter contato direto com o nativo desta língua. No entanto, existem fatores no ensino de línguas no Brasil que precisam ser revistos para que esse processo realmente aconteça.

Por meio das crenças expostas, conclui-se que os professores acreditam que o processo de aprendizagem depende exclusivamente do professor, ou melhor, de fatores extrínsecos, não levando em consideração que esse processo também é intrínseco. Observo que o reflexo desta crença em sala de aula pode gerar barreiras entre o professor e o aluno, pois o professor atribui parte da responsabilidade sobre a aprendizagem ao aluno e o aluno atribui a responsabilidade total ao professor. Esse é um dos fatores que prejudica professores, bem como alunos, nos mais variados contextos de ensino.

Essas crenças são referentes às práticas de ensino e aprendizagem vivenciadas durante o percurso de suas vidas acadêmicas, uma vez que esses docentes as ressaltam constantemente em suas narrativas de aprendizagem de LI, e em decorrência desses fatos, os professores acreditam que tanto o ensino quanto a aprendizagem adquirida por eles ficaram a desejar.

As crenças detectadas nas subseções supracitadas remetem a uma visão de ensino provavelmente ofertado aos professores pesquisados como tecnicista, alinhando-se aos pensamentos de Kumaravadivelu (2003), o qual discute sobre ensino e formação de professores, apresentando a vertente designada como técnica passiva e que era colocada em prática a partir de criações resultantes de pesquisas empíricas feitas por especialistas do campo educacional, as quais eram implantadas e, por conseguinte, colocadas em exercício pleno nos programas de formação de professores.

Por fim, estou ciente de que o grau de complexidade apresentado pela educação na atualidade envolve múltiplos fatores, não sendo, portanto, o insucesso 
do ensino de LE/LI resultado somente da forma equivocada com que algumas instituições de formação de professores colocam em prática seus currículos. Todavia, acredito que, para começar a fazer a diferença na educação nacional, no sentido de melhorar a qualidade desta, é necessário que repensemos e/ou reflitamos acerca da forma como o processo de formação de professores de línguas vem sendo desempenhado nas instituições de ensino superior. E, sob esse ponto de partida, buscar subsídios inovadores para a formação dos licenciandos, como os paradigmas crítico-reflexivo; sociocultural; do aluno-professor como intelectual crítico; sob a visão de comunidade de práticas; do posicionamento crítico do licenciando concernente ao conhecimento e práticas de ensino apresentadas durante o processo de formação (FREITAS, 2004; VIEIRA-ABRAHÃO, 2012; CRISTOVÃO, 2013; GIMENEZ, 2013a, 2013b; SILVA, 2013); para enfrentar os grandes obstáculos que se encontram no contexto de sala de aula.

$\mathrm{Na}$ sequência, encontram-se as conclusões e considerações finais deste estudo, retomando os objetivos e discorrendo sobre os resultados evidenciados.

\section{CONSIDERAÇÓES FINAIS}

Sob o viés do arcabouço teórico de crenças e formação docente de línguas, especificamente de LE/LI neste estudo, centralizou-se a lente na análise das crenças desveladas por professores sobre o processo de aprendizagem de Língua Inglesa, a partir de suas narrativas de aprendizagem. No presente estudo, valeu-se da pesquisa de natureza qualitativa do tipo interpretativista, pois o objetivo foi o de produzir um relato descritivo, interpretativo, exploratório das narrativas de aprendizagem de Língua Inglesa de professores de LI, no intuito de identificar as crenças elucidadas pelos mesmos, nos seus rememorandos das empreitadas vivenciadas na construção de seus conhecimentos de LE/LI.

Os resultados aqui apresentados autorizam o delineamento de algumas considerações e implicações para a prática educacional no intento de promover uma reflexão relativa à formação de professores de línguas. Apreendeu-se que as crenças desveladas por meio das narrativas de aprendizagem dos professores são prova de que uma boa formação docente de línguas é essencial para o percurso profissional do educador em serviço, para que seja possível evitar eventuais crenças sobre o processo de aprendizagem de LE/LI como as levantadas neste artigo. No entanto, se reconhece que, para que esta tão ambicionada formação ocorra efetivamente, é necessário que professores formadores, bem como professores em formação, percorram caminhos de incertezas, onde muitos desafios os aguardam. É um percurso por se fazer ainda, mas imprescindível que seja feito.

Foi possível constatar que o curso de Letras não oferece, ainda, uma formação que supra a demanda necessária para um ensino de línguas verdadeiramente efetivo, contemplando não somente todas as habilidades da LE/LI, mas outrossim a história e a cultura inerentes à língua. $\mathrm{O}$ reflexo dessa formação limitada foi percebida, igualmente, nesta pesquisa, em que os professores continuam utilizando metodologias defasadas no contexto de sala de aula, o que gerou crenças nos 
participantes desta investigação de que não se aprende LE/LI na escola pública. Entendo que esta problemática esteja gerando um círculo vicioso entre as lacunas deixadas pelo curso de Letras durante a preparação dos profissionais que atuarão no ensino de línguas, as quais refletem na prática pedagógica desses profissionais no âmbito real de uso desse processo de ensino. E, em consequência desses fatos, os alunos que passam pela aquisição desse ensino e aprendizagem de LE/LI feitos com inúmeros lapsos, ao chegarem em um curso de Letras, por exemplo, terão fortes influências negativas através de crenças concernentes à aprendizagem de LI, suscitando um desconsenso entre professor e aluno.

Apreendi que houve um conflito nas crenças dos professores, já que alguns acreditam que se aprende LI no curso de idiomas, no entanto, outros descreem que se aprende LE/LI no Brasil, creem que se aprende no país onde se fala essa LE. A crença sobre o papel do professor como detentor de conhecimento ainda permanece viva, o que é um ponto negativo para o professor de línguas, uma vez que esse fator é prejudicial na empreitada do ensino e aprendizagem de LE/LI. $\mathrm{O}$ risco de se gerar entraves entre o professor e o aluno, em consequência dessa crença, é muito alto. É preciso que o professor reflita juntamente com seus alunos sobre a distribuição de seus respectivos papéis em sala de aula, no fito de fomentar a conscientização de que a responsabilidade sobre a aprendizagem não recai apenas sobre ele.

Destarte, uma agenda de pesquisa que investigue as crenças sobre o processo de ensino e aprendizagem de línguas alusivas a aspectos específicos e que priorizem o contexto, pode ser acentuadamente significativa com vistas a alcançar avanços na direção de um ensino mais eficaz, instituído por profissionais comprometidos com a educação linguística, de modo a possibilitar que o aluno, adquira, de fato, o domínio de uma segunda língua, mais especificamente a Língua Inglesa, e torne-se apto a comunicar-se com maior eficiência na sociedade globalizada e altamente tecnológica, onde esta língua prevalece.

\section{REFERÊNCIAS}

ABELSON, R. Differences between belief systems and knowledge systems. Cognitive Science, v.3, p.355-366, 1979.

ALMEIDA FILHO, J. C. P. Dimensões comunicativas no ensino de línguas. Campinas: Pontes, 1993.

ANDRÉ, M. E. D. A. Etnografia da prática escolar. Campinas, Papirus, 1995.

BARCELOS, A. M. F. A cultura de aprender língua estrangeira (inglês) de alunos de Letras. Dissertação (Mestrado em Linguística Aplicada), Instituto de Estudos da Linguagem, UNICAMP, Campinas, SP, 1995.

. Crenças sobre aprendizagem de línguas, Linguística Aplicada e ensino de línguas.

Linguagem \& Ensino, v.7, n.1, p.123-156. 2004. 
Cognição de professores e alunos: tendências recentes na pesquisa de crenças sobre o ensino e aprendizagem de línguas. In: BARCELOS, A. M. F.; ABRAHÃO, M. H. V. (Orgs.). Crenças e ensino de línguas: foco no professor, no aluno e na formação de professores. Campinas: Pontes, 2006.

Reflexões acerca da mudança de crenças sobre ensino e aprendizagem de línguas.

Revista Brasileira de Linguística Aplicada, v.7, n. 2, p.109-138. 2007.

BOGDAN, R.; BIKLEN, S. Investigação qualitativa em educação: uma Introdução à teoria e aos métodos. Coleção da Educação. Portugal: Porto Editora, 1994.

BOURDIEU, P. A economia das trocas simbólicas. São Paulo: Perspectivas, 1987.

Language and Symbolic Power. Cambridge: Polity Press, 1991.

BOMFIM, B. B. S. B. Crenças em relação à formação inicial de professores de Inglês e a prática de ensino de uma professora formadora. Dissertação (Mestrado em Linguística Aplicada), Instituto de Letras, UNB, Brasília, DF, 2008.

COELHO, H. S. H. É possível aprender inglês em escola pública? Crenças de professores e alunos sobre o ensino de inglês em escolas públicas. Dissertação (Mestrado em Estudos Linguísticos), Faculdade de Letras, UFMG, Belo Horizonte, MG, 2005.

CRISTOVÃO, V. L. L. In: SILVA, K. A.; ARAGÃO, R. C. (Orgs.). Conversas com formadores de professores de línguas: avanços e desafios. Campinas, SP: Pontes Editores, 2013.

DEL PRETTEE, Z. A. P; DEL PRETTE, A. Psicologia das habilidades sociais: terapia e educação. Petrópolis, RJ: Vozes, 1999.

DEWEY, J. How we think. Lexington: D. C. Health and Company, 1933.

FÉLIX, A. Crenças do professor sobre o melhor aprender de uma língua estrangeira na escola. Dissertação (Mestrado em Linguística Aplicada), Instituto de Estudos da Linguagem, UNICAMP, Campinas, SP, 1998.

FREITAS, M. A. Educação e ensino de língua estrangeira hoje: implicações para a formação de seus respectivos profissionais e aprendizes. In: VIEIRA-ABRAHÃO, M. H. (org.) Prática de ensino de língua estrangeira: experiências e reflexões. Campinas, SP: Pontes Editores, Arte Língua, 2004.

GATTI, B. A. Formação de professores no Brasil: características e problemas. Revista Educação \& Sociedade, v.113, n.31, p.1355-1379. 2010.

GHEDIN, E. Professor reflexivo: da alienação da técnica à autonomia da crítica. In: PIMENTA, S. G.; GHEDIN, E. (orgs.) Professor reflexivo no Brasil: gênese e crítica de um conceito. 2. ed., São Paulo: Cortez, 2002.

GIMENEZ, T. Formação de professores de línguas no Brasil: avanços e desafios. In: SANTOS, L. I. S.; SILVA, K. A. (Orgs.). Linguagem, ciência ensino: desafios regionais e globais. Campinas, SP: Pontes Editores, 2013a. 

In: SILVA, K. A.; ARAGÃO, R. C. (Orgs.). Conversas com formadores de professores de línguas: avanços e desafios. Campinas, SP: Pontes Editores, 2013b.

KRUGER, H. R. Ação e crenças. Arquivos Brasileiros de Psicologia, v.45, n.3-4, p.311, 1993.

KUMARAVADIVELU, B. Beyond Methods: Macrostrategies for Language Teaching. New Haven: Yale University, 2003.

LEFFA, V. J. A. A look at students' concept of language learning. Trabalhos em Linguística Aplicada, v.17, p.57-65. 1991.

MATEUS, E. F. Supervisão de estágio e formação do professor de inglês.

Dissertação (Mestrado em Educação), Centro de Educação, Comunicação e Artes, UEL, 1999.

NESPOR, J. The role of beliefs in the practice of teaching. Journal of Curriculum Studies, v.19, p.317-328, 1987.

PACHECO, J.A. O Pensamento e a Ação do Professor. Lisboa: Porto Editora, 1995.

PAIVA, V. L. M. O.. O. Banco de dados do Projeto Aprendendo com Memórias de Falantes e Aprendizes de Língua Estrangeira (AMFALE). Universidade Federal de Minas Gerais. Disponível em: www.veramenezes.com/amfale.htm. Acesso em: 02/03/2017.

PEIRCE, C. S. The fixation of belief. In: WEINER, P. P. (Org.) Charles S. Peirce: Selected writings. New York: Dover, 1958.

POSNER, G. J. et al. Accommodation of a scientific conception: toward a theory of conceptual change. Science Education, v.66, n.2, p.211-227, 1982.

RAYMOND, A.M; SANTOS, V. Pre-service elementary teachers and self-reflection: how innovation in Mathematics teacher preparation challenges mathematics beliefs. Journal of Teacher Education, v.46, n.1, p.30-45,1995.

ROCHA, M. S. Cognições de futuros e atuais professores sobre como motivar aluno. Dissertação (Mestrado), Centro de Comunicação de Artes. Universidade Estadual de Londrina, 2002.

RODRIGUES, J. M. V. Crenças e experiências de aprendizagem de LE (inglês) de alunos de centros interescolares de línguas: um estudo de caso. Dissertação (Mestrado em Linguística Aplicada), Instituto de Letras, UNB, Brasília, DF, 2006.

SADALLA, A. M. F. A. Com a palavra, a professora: suas crenças, suas ações. Campinas: Alínea, 1998.

SANTOS, D. A. G. Crenças sobre o ensino-aprendizagem de inglês na atualidade: um estudo com professores do ensino médio. Dissertação (Mestrado em Estudos de Linguagem), Instituto de Linguagens, UFMT, Cuiabá, MT, 2010. 
SILVA, K. A. Crenças e aglomerados de crenças de alunos ingressantes em Letras (Inglês). Dissertação (Mestrado em Linguística Aplicada), Instituto de Estudos da Linguagem, UNICAMP, Campinas, SP, 2005. . ARAGÃO, R. C. (Orgs.). Conversas com formadores de professores de línguas: avanços e desafios. Campinas, SP: Pontes Editores, 2013.

SIMÕES, G. M. S. O Impacto do Estágio nas Crenças Pedagógicas de Professores de inglês em Formação. Tese (Doutorado em Estudos Linguísticos), Instituto de Biociências, Letras e Ciências Exatas da Universidade Estadual Paulista, UNESP, São José do Rio Preto, SP, 2011.

SIQUEIRA, D. S. P. Diversidade, ensino e linguagem: que desafios e compromissos aguardam o profissional de letras contemporâneo? Línguas \& Letras, v.24, n.13, p. 3566. 2012.

PORTO, Y. S. Formação continuada: a prática pedagógica recorrente. In: MARIN, A. J. (Org.). Educação continuada. 2. ed., Campinas, SP: Papirus, 2004.

VIEIRA-ABRAHÃO, M. H. A formação do professor de línguas de uma perspectiva sociocultural. Signum: Estudos da Linguagem, v.15, n.2, p.457-480. 2012.

ZOLNIER, M. C. A. P. Língua Inglesa: expectativas e crenças de alunos e de uma professora do ensino fundamental. Dissertação (Mestrado em Linguística Aplicada), Instituto de Estudos da Linguagem, UNICAMP, Campinas, SP, 2007. 